\title{
Toxoplasma gondii cathepsin proteases are undeveloped prominent vaccine antigens against toxoplasmosis
}

\author{
Guanghui Zhao ${ }^{1}$, Aihua Zhou ${ }^{2 *}$, Gang Lv ${ }^{1}$, Min Meng ${ }^{1}$, Min Sun ${ }^{1}$, Yang Bai ${ }^{1}$, Yali Han ${ }^{1}$, Lin Wang ${ }^{1}$, Huaiyu Zhou' \\ Hua Cong ${ }^{1}$, Qunli Zhao ${ }^{1}$, Xing-Quan Zhu $^{3}$ and Shenyi He ${ }^{1^{*}}$
}

\begin{abstract}
Background: Toxoplasma gondii, an obligate intracellular apicomplexan parasite, infects a wide range of warmblooded animals including humans. T. gondii expresses five members of the C1 family of cysteine proteases, including cathepsin B-like (TgCPB) and cathepsin L-like (TgCPL) proteins. TgCPB is involved in ROP protein maturation and parasite invasion, whereas TgCPL contributes to proteolytic maturation of proTgM2AP and proTgMIC3. TgCPL is also associated with the residual body in the parasitophorous vacuole after cell division has occurred. Both of these proteases are potential therapeutic targets in T. gondii. The aim of this study was to investigate $\mathrm{TgCPB}$ and $\mathrm{TgCPL}$ for their potential as DNA vaccines against T. gondii.
\end{abstract}

Methods: Using bioinformatics approaches, we analyzed TgCPB and TgCPL proteins and identified several linear-B cell epitopes and potential Th-cell epitopes in them. Based on these results, we assembled two single-gene constructs (TgCPB and TgCPL) and a multi-gene construct (pTgCPB/TgCPL) with which to immunize BALB/c mice and test their effectiveness as DNA vaccines.

Results: TgCPB and TgCPL vaccines elicited strong humoral and cellular immune responses in mice, both of which were Th-1 cell mediated. In addition, all of the vaccines protected the mice against infection with virulent T. gondii $\mathrm{RH}$ tachyzoites, with the multi-gene vaccine ( $\mathrm{pTg} \mathrm{CPB} / \mathrm{TgCPL}$ ) providing the highest level of protection.

Conclusions: T. gondii CPB and CPL proteases are strong candidates for development as novel DNA vaccines.

Keywords: Toxoplasma gondii, Cathepsin proteases, Bioinformatics, Vaccine, Toxoplasmosis

\section{Background}

The obligate intracellular apicomplexan parasite Toxoplasma gondii infects a wide range of warm-blooded animals and causes the anthropozoonotic disease known as toxoplasmosis on a worldwide scale $[1,2]$. T. gondii infection is usually invisible to the host, causing no symptoms or mild ones; however, severe disease complications can occur in immunocompromised individuals and newborns $[3,4]$. Toxoplasmic encephalitis can emerge as a lifethreatening condition in patients infected with the human

\footnotetext{
* Correspondence: zhouah@sdu.edu.cn; shenyi.he@hotmail.com

${ }^{2}$ Department of Pediatrics, Provincial Hospital Affiliated to Shandong University, Shandong University School of Medicine, Jinan, Shandong Province 250021, P R China

'Department of Parasitology, Shandong University School of Medicine, Jinan, Shandong Province 250012, P R China

Full list of author information is available at the end of the article
}

immunodeficiency virus when reactivation of the cyst stage of T. gondii occurs in the brain [5]. In addition, animal studies show that $T$. gondii infection can have a farreaching influence on host behavior, neuronal function and mate choice. Brain cysts in rats that are chronically infected with $T$. gondii alter the rats' exploratory and risk taking behavior and unconditioned fear responses, which can lead to greater opportunities for transmission of the parasite from the intermediate rodent host to the definitive host, the cat [6]. T. gondii can also enhance the sexual attractiveness of infected male rats [7]. T. gondii tachyzoites actively manipulate $\mathrm{Ca}^{2+}$ signaling upon glutamate stimulation, leading to neuronal hypo- or hyperresponsivity in the host [8]. Unfortunately, there are no drug treatments available to cure toxoplasmosis. In recent years, the possibility that DNA vaccines, which have the capacity to induce continuous and strong protective

\section{Biomed Central}


immune responses, could be an option for eliminating this ubiquitous parasite has been raised $[9,10]$.

An important design principle for DNA vaccines is the selection of parasite proteins involved in the host cell invasion process by $T$. gondii; therefore, many researchers are working to identify the relevant proteins that may be developed as vaccines against toxoplasmosis [11].

Cysteine proteases play many specialized roles in the body, including endocytosis-related polypeptide degradation [12], tumor invasion [13] and TNF $\alpha$-induced apoptosis [14]. More importantly, cysteine proteases are important for the growth and survival of apicomplexan parasites that infect humans. T. gondii expresses five members of the $\mathrm{C} 1$ family of cysteine proteases, including one cathepsin B-like (TgCPB), one cathepsin L-like (TgCPL), and three cathepsin C-like (TgCPC1, 2 and 3) proteases [15]. Among these, $\mathrm{TgCPB}$ and $\mathrm{TgCPL}$ are mainly expressed in the vacuolar compartment, but a tiny amount of TgCPL has been identified in the late endosome [16-19]. These proteases are thought to function in protein degradation and play specialized roles in the maturation of invasion-related proteins. $\operatorname{TgCPB}$ is involved in ROP protein maturation and parasite invasion [16]. In contrast, TgCPL contributes to proteolytic maturation of proTgM2AP and proTgMIC3, and is also associated with the residual body in the parasitophorous vacuole after cell division [20-23].

T. gondii cathepsins are considered potential therapeutic targets based on the results of the following genetic and inhibitor studies: antisense inhibition of TgCPB expression or treatment with cathepsin inhibitors diminished parasite replication, cell invasion and infection in vivo [16,24]; genetic disruption of TgCPL diminished parasite cell invasion and growth [17]; and, the cathepsin inhibitor morpholinurea-leucyl-homophenyl-vinyl sulfone phenyl inhibited parasite invasion by blocking the release of invasion proteins from microneme secretory organelles [25,26]. To our knowledge, no studies have described the induction of protective immune responses against $T$. gondii $\mathrm{CPB}$ and $\mathrm{CPL}$ in the host. We propose that a DNA vaccine construct based on TgCPB and TgCPL could be a useful tool against disease caused by $T$. gondii.

Hence, in this study, we used bioinformatics approaches to analyze $\mathrm{TgCPB}$ and $\mathrm{TgCPL}$, the results of which identified a large number of linear-B cell epitopes and potential Th-cell epitopes on these proteases. This suggested the possibility that TgCPB and TgCPL could be used as vaccines. Based on the results of the epitope analyses, $\mathrm{pTgCPB}$ and $\mathrm{pTgCPL}$ were constructed as single-gene vaccines and $\mathrm{pTgCPB} / \mathrm{TgCPL}$ as a multigene vaccine, and their immunogenicity, protective efficacy, and potential as vaccine candidates against T. gondii infection were examined in laboratory mice.

\section{Methods}

Prediction of protein secondary structure and linear-B cell epitopes

Epitopes are the foundation of protein antigenicity that determines antigen specificity [27,28]. There are many types of epitope prediction methods in use, including hydrophilicity, accessibility, antigenicity, flexibility, charge distribution and secondary structure [29-34]. Despite the lack of an infallible method to predict antigenic epitopes, several rules can be followed to determine which peptide fragments of a protein are likely to be antigenic. Firstly, antigenic epitopes should be located in solvent-accessible regions and contain both hydrophobic and hydrophilic residues. Secondly, peptides lying in long loops connecting secondary structure motifs should be selected preferably, while peptides located in helical regions should be avoided. Whenever possible, peptides that are in the $\mathrm{N}$ - and $\mathrm{C}$-terminal regions of the protein should be chosen because they are usually solvent accessible and unstructured.

According to the rules outlined above, we analyzed the linear-B cell epitopes of TgCPB and TgCPL using DNAStar software and chose peptides that have good hydrophilicity, high accessibility, satisfactory flexibility and strong antigenicity. Thereafter, we used DNAMAN software to search for linear-B cell epitopes in the TgCPB and TgCPL amino acid sequences.

\section{Prediction of Th-cell epitopes}

$T$. gondii is an obligate intracellular parasite; hence, cellular immunity mediated by $\mathrm{T}$ cells plays an important role in T. gondii infection [35]. To develop an effective vaccine against toxoplasmosis, it is necessary to elucidate which type of Th cell-mediated immune response is necessary. Predicting Th cell epitopes is currently rather complicated and the results are ambiguous; however, there are some rules that can be used to predict Th cell epitopes [36,37]. Here, we used the Immune Epitope Database (http://tools.immuneepitope.org/analyze/html/ mhc_II_binding.html) online service to predict the half maximal inhibitory concentration $\left(\mathrm{IC}_{50}\right)$ values of peptides binding to the major histocompatibility complex (MHC) class II molecules of TgCPB and TgCPL. We also used SYFPEITHI (http://www.syfpeithi.de/Scripts/ MHCServer.dll/EpitopePrediction.htm) to determine the ligation strength to a defined HLA (or H2) type for TgCPB and TgCPL. Note that such binding to MHC is necessary but not sufficient for recognition by $\mathrm{T}$ cells.

\section{Parasites and mice}

Female 6-week-old BALB/c mice were purchased from Shandong University Laboratory Animal Center. All mice were maintained under specific pathogen-free conditions. All of the animal experiments were approved by 
the Ethics Committee on Animal Experiments of the Medical School of Shandong University.

The $T$. gondii RH strain was harvested from the peritoneal fluid of the BALB/c mice $72 \mathrm{~h}$ after infection, and was washed by centrifugation and resuspended in sterile PBS. Half of the T. gondii tachyzoite suspension was used to extract total RNA and genomic DNA, while the other half was used to prepare soluble tachyzoite antigens (STAg) using an ultrasonic disintegrator. STAg preparations were aliquoted and stored at $-80^{\circ} \mathrm{C}$ until use.

\section{Construction of expression plasmids}

The whole $\operatorname{TgCPB}$ gene was amplified from $T$. gondii total RNA by reverse transcription polymerase chain reaction (PCR) using the two primer pairs shown below. $\operatorname{TgCPB}$ for prokaryotic expression used the following primers plasmid construction: 5'-cgGAATTCATGGAGGGGCGAAAGTC3' (forward) and 5'-ccgCTCGAGCTACATTTCTCTC TCCTCTTCTG-3' (reverse), both of which contain EcoRI/ XhoI restriction sites (underlined). Plasmid construction for eukaryotic expression of $\mathrm{TgCPB}$ consisted of $5^{\prime}$-ataagaat GCGGCCGCATGGAGGGGCGAAA-GTC-3' (forward) and 5'-ccgCTCGAGCTACATTTCTCTCTCCTCTTCTG$3^{\prime}$ (reverse), both of which contain $\mathrm{Not} \mathrm{I} / \mathrm{XhoI}$ restriction sites (underlined).

The whole TgCPL gene was PCR amplified from of $T$. gondii genomic DNA using the two primer pairs described below. Prokaryotic expression plasmid construction for TgCPL used the following primers: 5'-cgGAAT TCATGGACAGCAGCGAGACGC-A-3' (forward) and 5'-ccgCTCGAGTCACATCACGGGGAAAGACG-3' (reverse); EcoRI and XhoI restriction sites are underlined. Eukaryotic expression plasmid construction for TgCPL used the following primers: 5'-ccAAGCTTATGGA CAGCA-GCGAGACGCA-3' (forward) and 5' -gcTCTA GATCACATCACGGGGAAAGACG-3' (reverse); HindIII and $X b a I$ restriction sites are underlined.

The PCR products for both genes were cloned into a pEASY-T1 vector (TransGen Biotech, China) to generate a recombinant cloning plasmid. After sequencing, TgCPB and TgCPL were subcloned into a eukaryotic expression plasmid pET-30a(+) (Novagen, USA) and the prokaryotic expression plasmid, pBudCE4.1 (Invitrogen, USA) to produce pET30a-TgCPB, pET30a-TgCPL, pBudCE4.1-TgCPB and pBudCE4.1-TgCPL. Finally, TgCPB and TgCPL were concurrently subcloned into the prokaryotic expression plasmid pBudCE4.1 to produce pBudCE4.1-TgCPBTgCPL.

\section{TgCPB and TgCPL expression in Escherichia coli and antigen production}

pET30a-TgCPB and pET30a-TgCPL constructs were used to transform E. coli BL21(DE3) cells, which were then grown in Luria-Bertani medium with kanamycin
(25 $\mu \mathrm{g} / \mathrm{mL})$. Synthesis of recombinant $\operatorname{TgCPB}$ and TgCPL proteins was induced using $1 \mathrm{mM}$ isopropyl- $\beta-\mathrm{D}-$ thiogalactoside for 6 or $8 \mathrm{~h}$ at $25^{\circ} \mathrm{C}$. The cells were then lysed and centrifuged at $4^{\circ} \mathrm{C}$ for $15 \mathrm{~min}$ at $10,000 \times g$. Recombinant proteins were then purified via binding of their carboxy terminal histidine tags to Ni-NTA resin (Sangon Biotech, China).

Experimental mice were subcutaneously immunized with $100 \mu \mathrm{g}$ of purified $\mathrm{rTgCPB}$ or $\mathrm{rTgCPL}$ prepared in equal volumes of Freund's complete adjuvant for the first immunization. The second and third immunizations contained $50 \mu \mathrm{g}$ of the purified protein in Freund's incomplete adjuvant. Samples of antisera were collected 2 weeks after the last immunization.

\section{Examination of antibody specificity by western blotting}

Sodium dodecyl sulfate-polyacrylamide gel electrophoresis (SDS-PAGE) and western blotting were used to investigate antibody specificity, as described previously [38]. STAg preparations were removed from the ultra-low temperature freezer and $500 \mathrm{ng}$ of each preparation was used for SDSPAGE. The separated protein bands were transferred onto polyvinylidene difluoride (PVDF) membranes (Millipore, USA), each of which was blocked with $5 \%$ w/v skimmed milk powder diluted in PBS for $2 \mathrm{~h}$ at room temperature before separate incubation with mouse anti-TgCPB or antiTgCPL antibodies, or pre-immune mouse sera (dilution 1:600). After a wash in PBS-Tween 20, each of the membranes was incubated with diluted goat anti-mouse IgG horseradish peroxidase (HRP)-labeled secondary antibody (1:10,000; Sigma, USA) for $1 \mathrm{~h}$. Parasite proteins were visualized using electrochemiluminescence reagents (Cowin Biotech, China).

\section{TgCPB and TgCPL expression in mammalian cells}

When the cell density reached 80-90\%, HEK293 cells were transfected with pBudCE4.1-TgCPB or pBudCE4.1TgCPL using Lipofectamine ${ }^{\mathrm{TM}} 2000$ reagent (Invitrogen, USA). After 24-h incubation, the cells were fixed with cold methanol for $20 \mathrm{~min}$ and protein expression was evaluated using an indirect fluorescence antibody test as previously described [39]. Briefly, anti-TgCPB or antiTgCPL antibodies were used as primary antibodies and a FITC-labeled goat anti-mouse IgG antibody (ZSGB-Bio, China) was used as the secondary antibody. After rinsing three times with PBS, the coverslips were immediately observed under a fluorescence microscope (Carl Zeiss, Germany). The cells were then lysed with RIPA Lysis Buffer (50 mM Tris, pH 7.4; $150 \mathrm{mM} \mathrm{NaCl} ; 1 \%$ Triton $\mathrm{X}-100 ; 1 \%$ sodium deoxycholate; $0.1 \%$ SDS) containing 1 $\mathrm{mM}$ of the protease inhibitor phenylmethanesulfonyl fluoride, after which they were centrifuged at $12,000 \times g$ for $10 \mathrm{~min}$, at either $24 \mathrm{~h}$ or $48 \mathrm{~h}$ post-transfection. 


\section{SDS-PAGE and western blot analysis}

Protein production from HEK293 cells was monitored by SDS-PAGE and western blotting. About $500 \mathrm{ng}$ of the purified $\mathrm{rTgCPB}$ or $\mathrm{rTgCPL}$ proteins were separated using SDS-PAGE. The separated protein bands were transferred onto PVDF membranes. The detailed procedures are the same as in the above section "Identification of the antibody specificity by western blotting".

\section{Animal experiments}

Five groups of BALB/c mice ( $\mathrm{n}=13$ each) were individually injected 4 times at two-weekly intervals with one of the following: PBS, pBudCE4.1, pTgCPB, pBudCE4.1TgCPL or pBudCE4.1-TgCPB-TgCPL. Two weeks after the final immunization, the mice were challenged by intraperitoneal (i.p.) injection of $100 \mu \mathrm{L}$ of PBS containing $1 \times 10^{4} \mathrm{~T}$. gondii tachyzoites and the survival time of each mouse was recorded.

\section{Antibody assays}

The levels of IgG antibodies against T. gondii were analyzed using an enzyme-linked immunosorbent assay (ELISA) [40]. The microtiter plates (Costar, USA) were coated with STAg (10 pmol/well) and incubated at $4{ }^{\circ} \mathrm{C}$ overnight. After washing three times with PBS-T, the plates were blocked with $1 \%$ bovine serum albumin for 1 $\mathrm{h}$ at $37^{\circ} \mathrm{C}$. The plates were washed a further three times and incubated with the mouse sera diluted in PBS for 1 $\mathrm{h}$ at $37^{\circ} \mathrm{C}$. After three washes, secondary goat antimouse IgG, IgG1 or IgG2a conjugated with HRP (Sigma) was added and incubated at $37^{\circ} \mathrm{C}$ for $1 \mathrm{~h}$. Immune complexes were revealed by incubating with orthophenylenediamine (Sigma) and $0.15 \% \mathrm{H}_{2} \mathrm{O}_{2}$ for $30 \mathrm{~min}$. Reactions were stopped by the addition of $2 \mathrm{M} \mathrm{H}_{2} \mathrm{SO}_{4}$ and read at $490 \mathrm{~nm}$ with an ELISA plate reader (EL800; Bio-Tek, USA). All samples were run in triplicate.

\section{Cytokine assays}

Cytokine levels were detected according to the previously described method [39]. Briefly, three mice per group on week 4 after the final immunization were euthanized and their spleens removed under sterile conditions. Viable splenocytes were dispensed into 96 -well plates at $37^{\circ} \mathrm{C}$ in $5 \% \mathrm{CO}_{2}$ and the cell-free supernatants were harvested and assayed for IL-4 levels at $24 \mathrm{~h}$, or at $72 \mathrm{~h}$ for IL-10, or at $96 \mathrm{~h}$ for IFN- $\gamma$ using an ELISA kit (R\&D Systems, USA).

\section{Statistical analyses}

Statistical analyses were performed using SPSS software. Antibody production and cytokine levels among the different groups were determined using a one-way analysis of variance. Survival times in the mice were compared using the Kaplan-Meier method. Values of $\mathrm{P}<0.05$ were considered statistically significant.
Table 1 Linear-B cell antigenic epitope prediction for TgCPB

\begin{tabular}{llll}
\hline Order & $\begin{array}{l}\text { Amino acid } \\
\text { position }\end{array}$ & Potential antigenic sequences & Score \\
\hline 1 & $325-346$ & LMPLSAQHTTSCCNAIHCASFG & 1.190 \\
2 & $6-30$ & SFRVLGTPLPFAALAAILLLGCMYT & 1.183 \\
3 & $57-86$ & AEDVLNAFVSPESVESLFDSIVAEQWATS & 1.176 \\
4 & $379-407$ & CWPYEVPFCAHHAKAPFPDCDATLVPRKT & 1.175 \\
5 & $118-127$ & GELLRLLLAD & 1.170 \\
6 & $147-160$ & RHIVRDSVLVSEKA & 1.164 \\
7 & $283-294$ & AFPACKDWGHV & 1.157 \\
8 & $453-489$ & GPVSGAFMVYEDFLSYKSGVKHVSGLPVGGHAIKII & 1.153 \\
9 & $196-204$ & SNAAVALIK & 1.130 \\
10 & $300-306$ & CGSCWAF & 1.108 \\
11 & $243-250$ & GTFLVNTK & 1.103 \\
12 & $225-236$ & EVSLRFRYLSLK & 1.092 \\
13 & $272-278$ & EPVPAHF & 1.091 \\
14 & $314-320$ & DRLCIRS & 1.084 \\
15 & $38-44$ & DSLFPLS & 1.078 \\
16 & $434-440$ & TSAYSLR & 1.067 \\
17 & $139-145$ & FRHLTHS & 1.061 \\
18 & $420-426$ & ADNVHPF & 1.060 \\
19 & $362-367$ & KGWTG & 1.055 \\
20 & $260-265$ & MPLPAK & 1.045 \\
21 & $520-525$ & MGQCGI & 1.039 \\
\hline & & & \\
\hline
\end{tabular}

Table 2 Linear-B cell antigenic epitope prediction for TgCPL

\begin{tabular}{llll}
\hline Order & Amino acid position & Potential antigenic sequences & Score \\
\hline 1 & $60-82$ & RAWIALVAAAVSLLVFASFLIQW & 1.205 \\
2 & $364-372$ & DHGVLLVGY & 1.168 \\
3 & $142-151$ & KNNLVYIHTH & 1.152 \\
4 & $303-320$ & RAQSCEKWKILGFKDVP & 1.152 \\
5 & $89-100$ & AVFPPSPVEDHQ & 1.152 \\
6 & $35-44$ & PSPPFWTTR & 1.152 \\
7 & $187-209$ & KSHHLGVATELLNVLPSELPAGV & 1.141 \\
8 & $410-419$ & QCGLLLDASF & 1.138 \\
9 & $214-221$ & RGCVTPVK & 1.136 \\
10 & $6-12$ & THYVSFL & 1.130 \\
11 & $328-341$ & KAALAKSPVSIAIE & 1.120 \\
12 & $278-297$ & FQYVLDSGGICSEDAYPYLA & 1.119 \\
13 & $239-255$ & EGAHCAKTGKLVSLSEQ & 1.110 \\
14 & $226-232$ & CGSCWAF & 1.108 \\
15 & $347-362$ & FQFYHEGVFDASCGTD & 1.100 \\
16 & $113-127$ & FQDAFSSFQAMYAKS & 1.050 \\
17 & $175-180$ & RKYLGF & 1.035 \\
\hline
\end{tabular}


Table $3 \mathrm{IC}_{50}$ values for TgCPB and TgCPL peptide binding to MHC class II molecules obtained using the immune epitope database

\begin{tabular}{|c|c|c|c|}
\hline MHC II Allele ${ }^{1}$ & Start-Stop ${ }^{2}$ & Sequence $^{3}$ & $\begin{array}{l}\text { Percentile } \\
\text { Rank }^{4}\end{array}$ \\
\hline \multicolumn{4}{|l|}{$\operatorname{TgCPB}$} \\
\hline HLA-DRB1*01:01 & $10-24$ & LGTPLPFAALAAILL & 0.01 \\
\hline HLA-DRB1*01:01 & $71-85$ & ESLFDSIVAEQWAT & 6.21 \\
\hline HLA-DRB1*01:01 & $228-242$ & LRFRYLSLKDAKKLM & 4.99 \\
\hline HLA-DRB1*01:01 & $320-334$ & SQGKRLMPLSAQHTT & 2.74 \\
\hline HLA-DRB1*01:01 & $470-484$ & SGVYKHVSGLPVGGH & 1.58 \\
\hline $\mathrm{H} 2-\mathrm{IAb}$ & $8-22$ & RVLGTPLPFAALAAI & 3.83 \\
\hline $\mathrm{H} 2-\mathrm{IAb}$ & $59-73$ & DVLNAFVSPESVESL & 3.51 \\
\hline $\mathrm{H} 2-\mathrm{ABb}$ & $187-201$ & VFWESRPASSNAAVA & 0.91 \\
\hline $\mathrm{H} 2-\mathrm{Ab}$ & $300-314$ & CGSCWAFASTEAFND & 4.46 \\
\hline $\mathrm{H} 2-\mathrm{AB}$ & $549-563$ & LPGQRAAGARAGAHA & 3.19 \\
\hline $\mathrm{H} 2-\mathrm{IAd}$ & $15-29$ & PFAALAAILLLGCMY & 1.88 \\
\hline $\mathrm{H} 2-\mathrm{IAd}$ & $191-205$ & SRPASSNAAVALIKK & 4.34 \\
\hline $\mathrm{H} 2-\mathrm{IAd}$ & $227-241$ & SLRFRYLSLKDAKKL & 1.21 \\
\hline $\mathrm{H} 2-\mathrm{IAd}$ & $320-334$ & SQGKRLMPLSAQHTT & 3.19 \\
\hline $\mathrm{H} 2-\mathrm{IAd}$ & $428-442$ & QDTHKATSAYSLRSR & 2.52 \\
\hline H2-IEd & 182-196 & ETGEDVFWESRPASS & 17.89 \\
\hline H2-IEd & $226-240$ & VSLRFRYLSLKDAKK & 13.43 \\
\hline $\mathrm{H} 2-\mathrm{IEd}$ & $351-365$ & QPGMAWRWFERKGW & 4.77 \\
\hline $\mathrm{H} 2-\mathrm{IEd}$ & $399-413$ & DATLVPRKTPKCRKD & 16.82 \\
\hline $\mathrm{H} 2-\mathrm{IEd}$ & $432-446$ & KATSAYSLRSRDDVK & 9.89 \\
\hline \multicolumn{4}{|l|}{$\mathrm{TgCPL}$} \\
\hline HLA-DRB1*01:01 & $60-74$ & RAWIALVAAAVSLLV & 0.04 \\
\hline HLA-DRB1*01:01 & $46-60$ & YFWKKFLRQRNFTAR & 6.00 \\
\hline HLA-DRB1*01:01 & $117-131$ & FSSFQAMYAKSYATE & 2.74 \\
\hline HLA-DRB1*01:01 & $136-150$ & RRYAIFKNNLVYIHT & 3.24 \\
\hline HLA-DRB1*01:01 & $178-192$ & LGFKKSRNLKSHHLG & 5.20 \\
\hline $\mathrm{H} 2-\mathrm{Ab}$ & $27-41$ & RRGVRAGRPSPPFW & 1.49 \\
\hline $\mathrm{H} 2-\mathrm{ABb}$ & $59-73$ & ARAWIALVAAAVSLL & 3.37 \\
\hline $\mathrm{H} 2-\mathrm{IAb}$ & $85-99$ & EDDRAVFPPSPVEDH & 3.42 \\
\hline $\mathrm{H} 2-\mathrm{IAb}$ & $116-130$ & AFSSFQAMYAKSYAT & 5.68 \\
\hline $\mathrm{H} 2-\mathrm{AB}$ & $226-240$ & CGSCWAFSTTGALEG & 2.49 \\
\hline $\mathrm{H} 2-\mathrm{IAd}$ & $22-36$ & GELHQRRGVRAGRPS & 6.17 \\
\hline $\mathrm{H} 2-\mathrm{IAd}$ & $57-71$ & FTARAWIALVAAAVS & 0.14 \\
\hline $\mathrm{H} 2-\mathrm{IAd}$ & $117-131$ & FSSFQAMYAKSYATE & 2.63 \\
\hline $\mathrm{H} 2-\mathrm{IAd}$ & $318-332$ & DVPRRSEAAMKAALA & 0.01 \\
\hline $\mathrm{H} 2-\mathrm{IAd}$ & $395-409$ & RDGYMYMAMHKGEEG & 1.82 \\
\hline H2-IEd & $42-56$ & TTRTYFWKKFLRQRN & 7.05 \\
\hline $\mathrm{H} 2-\mathrm{IEd}$ & 174-188 & RRKYLGFKKSRNLKS & 13.03 \\
\hline $\mathrm{H} 2-\mathrm{IEd}$ & $202-216$ & PSELPAGVDWRSRGC & 28.28 \\
\hline $\mathrm{H} 2-\mathrm{IEd}$ & $309-323$ & KWKILGFKDVPRRS & 21.70 \\
\hline H2-IEd & $376-390$ & KESKKDFWIMKNSWG & 24.70 \\
\hline
\end{tabular}

${ }^{1} \mathrm{H} 2$-IAb, H2-IAd and H2-IEd alleles are mouse MHC class II molecules; the HLA-DRB1*01:01 allele is a human MHC class II molecule.

${ }^{2}$ We chose 15 amino acids for analysis each time.

${ }^{3} \mathrm{TgCPB}$ or $\mathrm{TgCPL}$ sequences.

${ }^{4}$ Low percentile $=$ high binding.
Table 4 Ligation strength analysis of TgCPB and TgCPL for MHC class II molecules using SYFPEITHI

\begin{tabular}{|c|c|c|c|}
\hline MHC II Allele ${ }^{1}$ & Start-Stop ${ }^{2}$ & Sequence $^{3}$ & Score $^{4}$ \\
\hline \multicolumn{4}{|l|}{$\mathrm{TgCPB}$} \\
\hline $\mathrm{H} 2-\mathrm{Ad}$ & $55-69$ & FSAEDVLNAFVSPES & 31 \\
\hline $\mathrm{H} 2-\mathrm{Ad}$ & $76-90$ & SIVAEQWATSGNLT & 27 \\
\hline $\mathrm{H} 2-\mathrm{Ad}$ & $412-426$ & KDCEEQAYADNVHPF & 27 \\
\hline $\mathrm{H} 2-\mathrm{Ad}$ & $117-131$ & AGELLRLLLADSEDM & 26 \\
\hline $\mathrm{H} 2-\mathrm{Ak}$ & $43-57$ & LSEDTSVDPRESFSA & 24 \\
\hline $\mathrm{H} 2-\mathrm{Ak}$ & $72-86$ & SLFDSIVAEQWATS & 24 \\
\hline $\mathrm{H} 2-\mathrm{Ak}$ & $149-163$ & IVRDSVLVSEKAFPS & 24 \\
\hline $\mathrm{H} 2-\mathrm{Ak}$ & $37-51$ & DDSLFPLSEDTSVDP & 22 \\
\hline $\mathrm{H} 2-\mathrm{Ed}$ & $313-327$ & NDRLCIRSQGKRLMP & 28 \\
\hline $\mathrm{H} 2-\mathrm{Ed}$ & $436-450$ & AYSLRSRDDVKRDMM & 28 \\
\hline $\mathrm{H} 2-\mathrm{Ed}$ & $229-243$ & RFRYLSLKDAKKLMG & 26 \\
\hline $\mathrm{H} 2-\mathrm{Ed}$ & $309-313$ & TEAFNDRLCIRSQGK & 24 \\
\hline H2-Ek & $86-100$ & SGNLTESAPRDRDSA & 24 \\
\hline H2-Ek & $313-327$ & NDRLCIRSQGKRLMP & 22 \\
\hline H2-Ek & $463-477$ & EDFLSYKSGVYKHVS & 22 \\
\hline H2-Ek & $37-51$ & DDSLFPLSEDTSVDP & 20 \\
\hline HLA-DRB1*0101 & $4-18$ & RKSFRVLGTPLPFAA & 35 \\
\hline HLA-DRB1*0101 & $13-27$ & PLPFAALAAILLLGC & 34 \\
\hline HLA-DRB1*0101 & $470-484$ & SGVYKHVSGLPVGGH & 33 \\
\hline HLA-DRB1*0101 & $71-85$ & ESLFDSIVAEQWA T & 32 \\
\hline \multicolumn{4}{|l|}{$\mathrm{TgCPL}$} \\
\hline $\mathrm{H} 2-\mathrm{Ad}$ & $60-74$ & RAWIALVAAAVSLLV & 31 \\
\hline $\mathrm{H} 2-\mathrm{Ad}$ & $68-82$ & AAVSLLVFASFLIQW & 30 \\
\hline $\mathrm{H} 2-\mathrm{Ad}$ & $192-206$ & GVATELLNVLPSELP & 30 \\
\hline $\mathrm{H} 2-\mathrm{Ad}$ & $58-72$ & TARAWIALVAAAVSL & 27 \\
\hline $\mathrm{H} 2-\mathrm{Ak}$ & $18-32$ & GLENGELHQRRGVRA & 22 \\
\hline $\mathrm{H} 2-\mathrm{Ak}$ & $146-160$ & VYIHTHNQQGYSYSL & 22 \\
\hline $\mathrm{H} 2-\mathrm{Ak}$ & $196-210$ & ELLNVLPSELPAGVD & 22 \\
\hline $\mathrm{H} 2-\mathrm{Ak}$ & $256-270$ & ELMDCSRAEGNQSCS & 20 \\
\hline $\mathrm{H} 2-\mathrm{Ed}$ & $311-325$ & VKILGFKDVPRRSEA & 30 \\
\hline $\mathrm{H} 2-\mathrm{Ed}$ & $44-58$ & RTYFWKKFLRQRNFT & 26 \\
\hline $\mathrm{H} 2-\mathrm{Ed}$ & $170-184$ & RDEFRRKYLGFKKSR & 26 \\
\hline $\mathrm{H} 2-\mathrm{Ed}$ & $369-383$ & LVGYGTDKESKKDFW & 26 \\
\hline H2-Ek & $310-324$ & WKILGFKDVPRRSE & 24 \\
\hline H2-Ek & $77-91$ & SFLIQWQGEDDRAVF & 22 \\
\hline H2-Ek & $365-379$ & HGVLLVGYGTDKESK & 22 \\
\hline H2-Ek & $6-20$ & THYVSFLNGEDDGLE & 20 \\
\hline HLA-DRB1*0101 & $59-73$ & ARAWIALVAAAVSLL & 34 \\
\hline HLA-DRB1*0101 & $60-74$ & RAWIALVAAAVSLLV & 31 \\
\hline HLA-DRB1*0101 & $195-209$ & TELLNVLPSELPAGV & 31 \\
\hline HLA-DRB1*0101 & $308-322$ & EKWKILGFKDVPRR & 30 \\
\hline
\end{tabular}

${ }^{1} \mathrm{H} 2$ - $\mathrm{Ad}, \mathrm{H} 2-\mathrm{Ak}, \mathrm{H} 2$-Ed and $\mathrm{H} 2$-Ek alleles are mouse MHC class II molecules; the HLA-DRB1*0101 allele is a human MHC class II molecule.

${ }^{2}$ We chose 15 amino acids for analysis each time.

${ }^{3} \mathrm{TgCPB}$ or $\mathrm{TgCPL}$ sequences.

${ }^{4}$ High score $=$ high binding. 

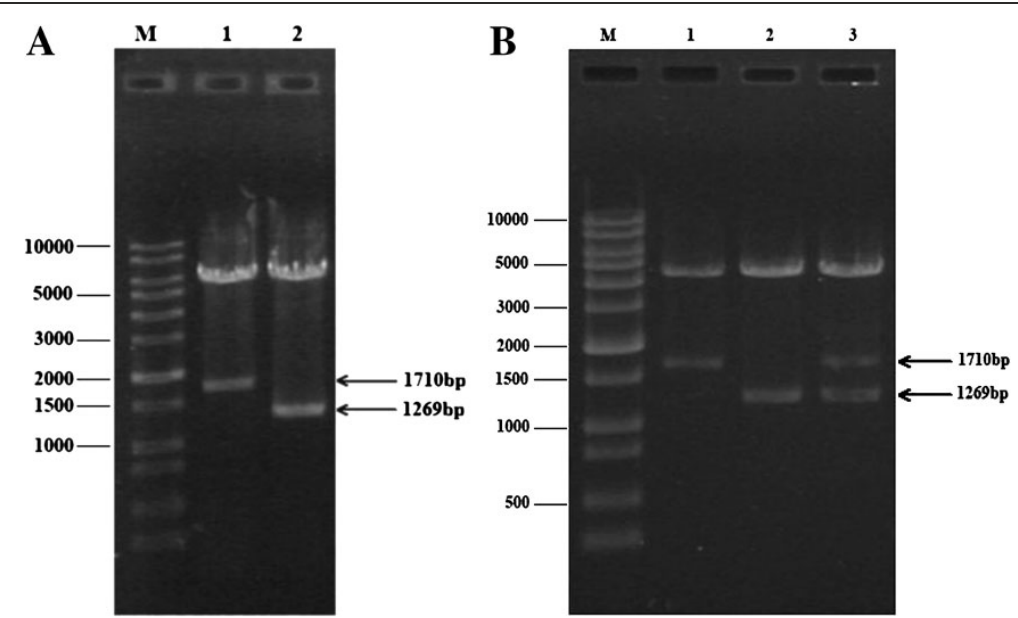

Figure 1 Recombinant cathepsin protease expression plasmids. (A) M: DNA size marker; Lane 1: recombinant pET30a-TgCPB plasmid digested with EcoRI and Xhol; Lane 2: recombinant PET30a-TgCPL plasmid digested with EcoRI and Xhol. (B) M: DNA size marker; Lane 1: recombinant pBudCE4.1-TgCPB plasmid digested with Notl and Xhol; lane 2: recombinant pBudCE4.1-TgCPL plasmid digested with Hindlll and Xbal; lane 3: recombinant pBudCE4.1-TgCPB-TgCPL plasmid digested with Notl, Xhol, Hindlll and Xbal.

\section{Ethics statement}

All experimental procedures using animals in the present study had received prior approval by the Institutional Animal Care and Use Committee of Shandong University under Contract 2011-0015. Humane endpoints to reduce pain or distress in the experimental animals were employed via euthanasia. Mice were monitored daily over 8 weeks for signs of toxoplasmosis, which included difficulties with their food and water intake, lethargy, or severe ascites. Mice that showed signs of illness were sacrificed immediately using $\mathrm{CO} 2$ gas; this involved placing the mice in a chamber and administering $\mathrm{CO} 2$ at a concentration of $60 \%$ to $70 \%$ over a 5-minute exposure time, after which the cervical dislocation method was sometimes used to ensure that effective euthanasia had occurred.

\section{Results}

Prediction of linear-B cell epitopes and Th-cell epitopes

The results of the prediction analyses indicated the presence of 21 potential epitopes on $\operatorname{TgCPB}$ and 17 on $\mathrm{TgCPL}$, as shown in Tables 1 and 2. The Th-cell epitopes on TgCPB and $\operatorname{TgCPL}$ that were identified by bioinformatic analyses are predicted to have the ability to bind strongly to MHC class II molecules (Tables 3 and 4). The binding strength of the interaction is known to influence the direction of Th cell differentiation, where, as the binding force increases, more cells tend to differentiate into Th- 1 cells $[41,42]$. As such, we speculate that $\mathrm{TgCPB}$ and $\mathrm{TgCPL}$ are likely to induce Th-1 cell-mediated immune responses.

\section{Prokaryotic and eukaryotic expression vectors for TgCPB} and TgCPL

Recombinant plasmids pET30a-TgCPB and pET30aTgCPL were digested with EcoRI and XhoI resulting in the correct sized fragments and indicating successful construction of the prokaryotic expression plasmids (Figure 1A). Similarly, restriction digests of pBudCE4.1TgCPB (NotI and XhoI), pBudCE4.1-TgCPL (HindIII and $X b a \mathrm{I})$, and the dual construct pBudCE4.1-TgCPB-TgCPL (NotI, XhoI, HindIII and XbaI) confirmed that the recombinant eukaryotic expression plasmids had been correctly made (Figure 1B).

Antibody specificity against $\mathrm{rTgCPB}$ and $\mathrm{rTgCPL}$ proteases PVDF membranes from western blots of STAg preparations were incubated separately with mouse anti-TgCPB or anti-TgCPL antibodies or pre-immune mouse sera. The results showed that the mouse anti-TgCPB and anti-TgCPL antibodies recognized proteins bands of about $62 \mathrm{kDa}$ and $47 \mathrm{kDa}$, which is consistent with the expected sizes of the $\mathrm{TgCPB}$ and $\mathrm{TgCPL}$ proteins, respectively (Figure 2).

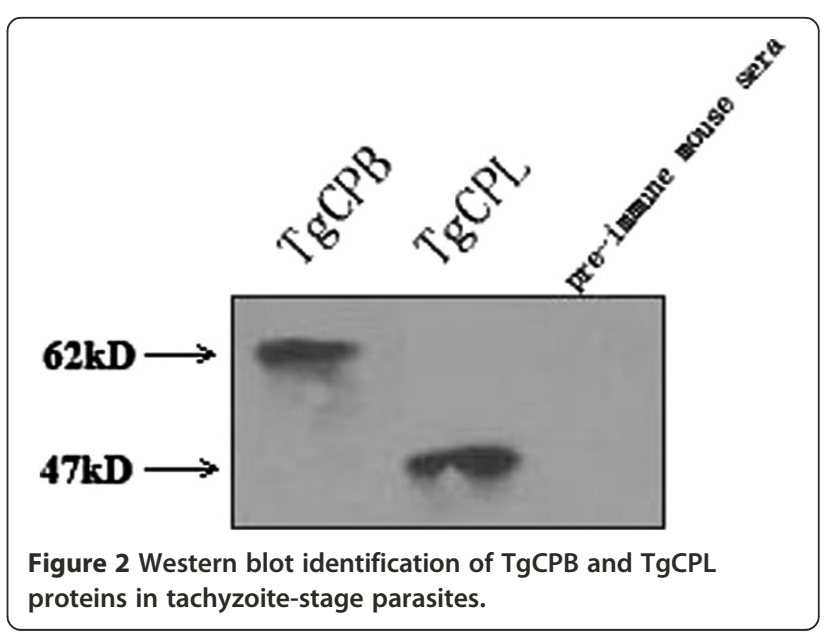



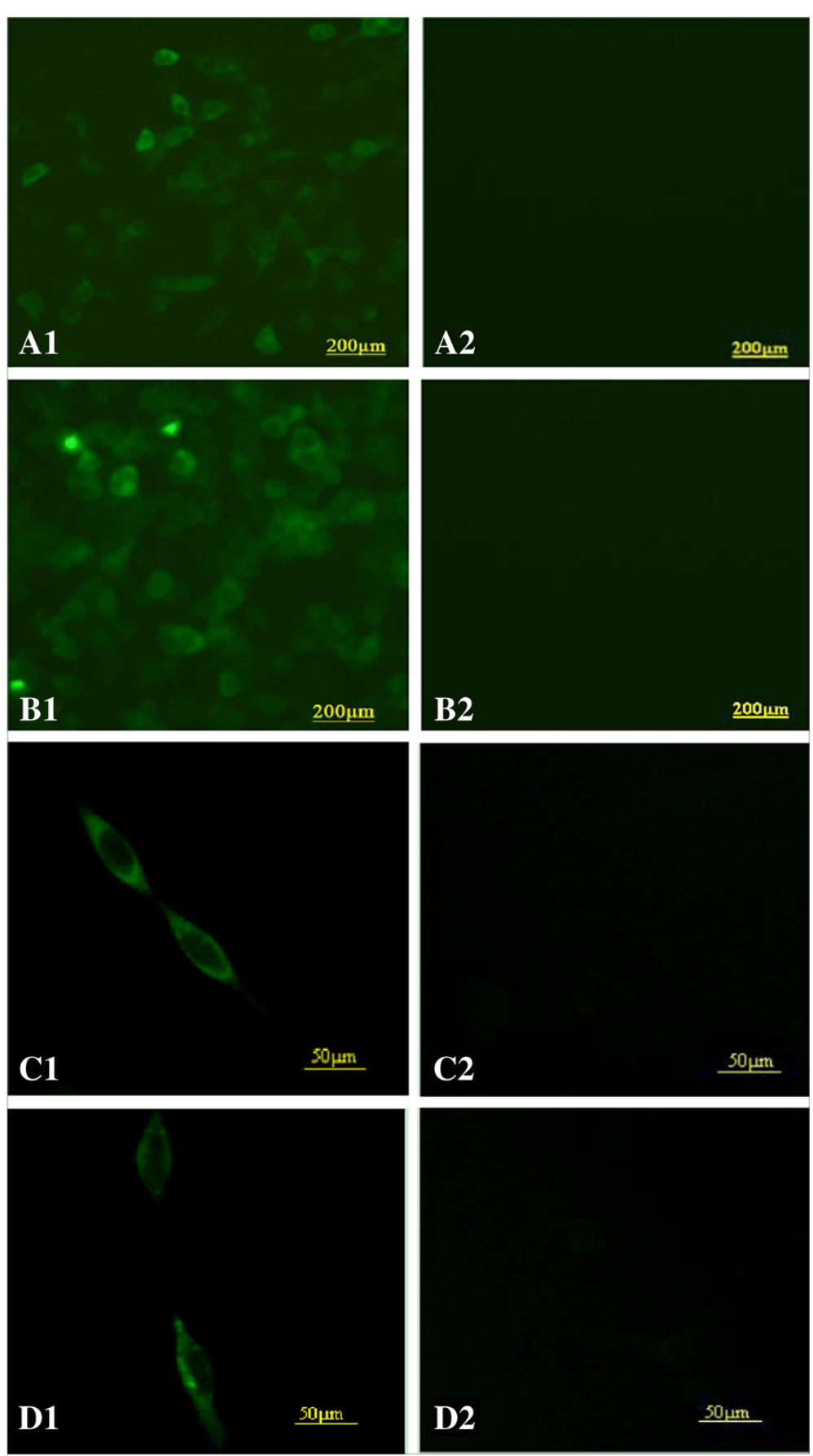

Figure 3 Indirect fluorescent antibody detection of recombinant TgCPB and TgCPL proteases on the surface of HEK293 cells. (A1) pTgCPB-transfected HEK293 cells; (A2) pBudCE4.1-transfected HEK293 cells. (B1) pTgCPL-transfected HEK293 cells; (B2) pBudCE4.1-transfected HEK293 cells. (C1) pTgCPB/TgCPL-transfected HEK293 cells where pTgCPB/TgCPL expression was detected using the anti-TgCPB antibody as the primary antibody; (C2) pBudCE4.1-transfected HEK293 cells where the anti-TgCPB antibody was used as the primary antibody. (D1) pTgCPB/ TgCPL-transfected HEK293 cells where the anti-TgCPL antibody was used as the primary antibody; (D2) pBudCE4.1-transfected HEK293 cells where the anti-TgCPL antibody was used as the primary antibody. High level of laser intensity was used for A1, A2, B1 and B2, lower level of laser intensity for C1, C2, D1 and D2. 


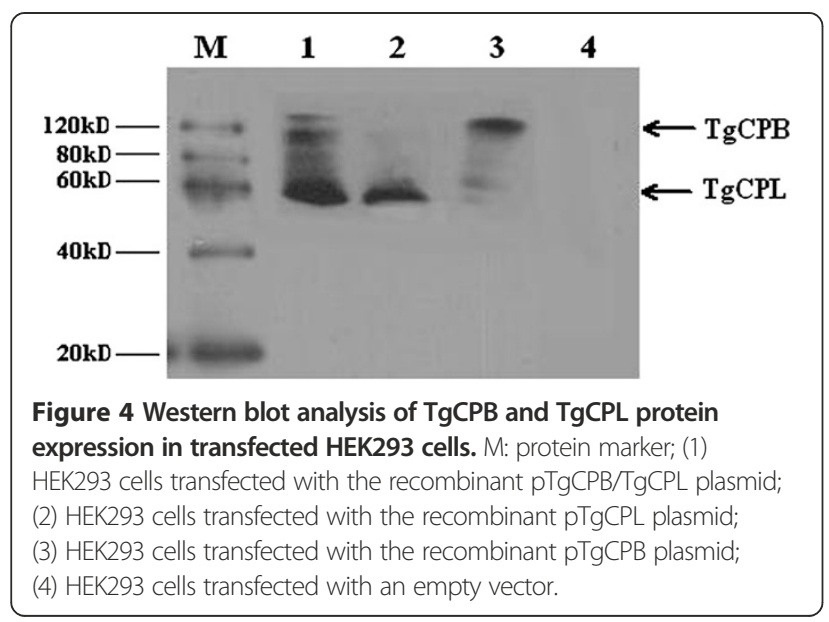

Identification of protein expression in HEK293 cells using immunofluorescence assay (IFA) and western blotting In vitro expression of $\mathrm{p} \operatorname{TgCPB}, \mathrm{pTgCPL}$ and $\mathrm{pTgCPB} /$ $\mathrm{TgCPL}$ were evaluated by IFAs at $48 \mathrm{~h}$ post-transfection. As shown in Figure 3, green fluorescence was observed in HEK293 cells, whereas no fluorescence was observed in the pBudCE4.1 vector transfected cells. Western blotting analysis confirmed expression of rTgCPB $(\sim 62 \mathrm{kDa})$ and $\mathrm{rTgCPL}$ $(\sim 47 \mathrm{kDa})$ in HEK293 cells transfected with pTgCPB or pTgCPL. Both proteins were detected in cells transfected with the dual expression vector, $\mathrm{p} \operatorname{TgCPB} / \operatorname{TgCPL}$ (Figure 4).

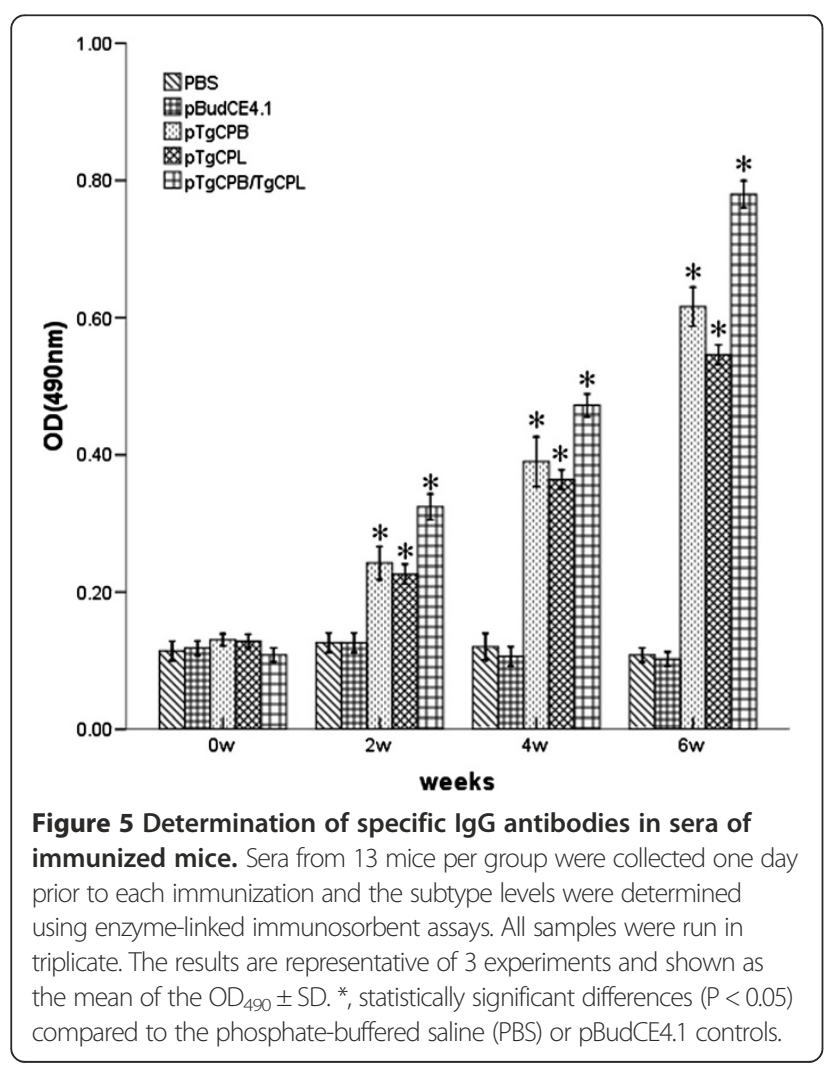

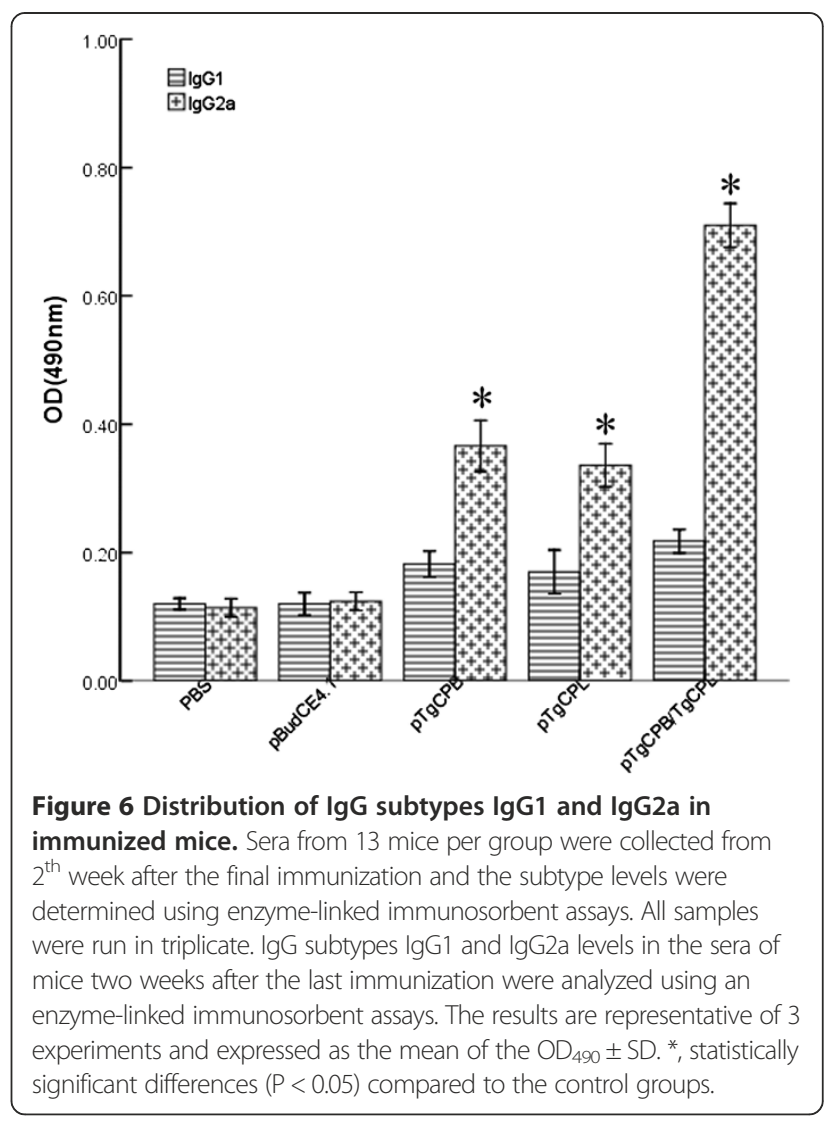

Antibody responses in immunized mice

High levels of immunoglobulin G (IgG) antibodies were observed in the experimental mice immunized with pTgCPB, pTgCPL, or pTgCPB/TgCPL. The antibody levels gradually increased with successive immunizations and were higher than those of the control groups, which were immunized with phosphate-buffered saline (PBS) or pBudCE4.1 (Figure 5). A significant difference was detected between the experimental groups and the control groups $(\mathrm{P}<0.05)$. IgG antibody levels in the $\mathrm{p} \operatorname{TgCPB} / \mathrm{TgCPL}$ group were higher than those of the

Table 5 Cytokine production by splenocyte ${ }^{\text {a }}$ cultures from immunized BALB/c mice

\begin{tabular}{llll}
\hline Group & \multicolumn{3}{c}{ Cytokine production $(\mathbf{p g} / \mathbf{m L})^{\mathbf{b}}$} \\
\cline { 2 - 4 } & IFN- $\boldsymbol{~}$ & IL-4 & IL-10 \\
\hline PBS & $47.59 \pm 4.63$ & $37.26 \pm 2.84$ & $44.34 \pm 2.77$ \\
PBudCE4.1 & $48.35 \pm 1.86$ & $33.70 \pm 3.29$ & $38.70 \pm 2.70$ \\
pTgCPB & $674.93 \pm 83.36^{*}$ & $32.58 \pm 3.72$ & $34.60 \pm 1.92$ \\
pTgCPL & $585.14 \pm 112.03^{*}$ & $32.34 \pm 3.87$ & $35.47 \pm 1.94$ \\
pTgCPB/TgCPL & $1182.23 \pm 94.28^{* \#}$ & $36.11 \pm 3.51$ & $34.57 \pm 2.14$
\end{tabular}

IFN, interferon; IL, interleukin, PBS, phosphate-buffered saline.

a Splenocytes were obtained from 3 mice per group and were collected at week 4 after the final immunization.

${ }^{b}$ Values for IFN- $\gamma$ at $96 \mathrm{~h}$. Values for IL-10 at $72 \mathrm{~h}$. Values for IL-4 at $24 \mathrm{~h}$. *Compared with the PBS-adjuvant or pBudCE4.1 controls $(\mathrm{P}<0.05)$; \# compared with $\mathrm{pTgCPB}$ or $\mathrm{pTgCPB}(\mathrm{P}<0.05)$. 
pTgCPB and pTgCPL groups $(\mathrm{P}<0.05)$. However, no statistical difference was detected between the pTgCPB and $\mathrm{pTgCPL}$ groups $(\mathrm{P}>0.05)$. These results indicate that the recombinant plasmids encoding $\operatorname{TgCPB}$ and TgCPL induced strong IgG antibody responses in the mice. Furthermore, the OD value for this group reached a high level two weeks after the third immunization.

IgG subclass (IgG1 and IgG2a) levels in all of the groups during the second week after the final immunizations were investigated to determine whether a Th1- or Th2-type response was elicited (Figure 6). An apparent predominance of IgG2a over IgG1 was observed in both the single-gene or multi-gene vaccine immunized mice, indicating a shift toward a Th1-type response. Furthermore, mice immunized with $\mathrm{pTgCPB} / \mathrm{TgCPL}$ generated higher IgG2a levels than those immunized with pTgCPB or pTgCPL alone $(\mathrm{P}<0.05)$. However, there was no significant difference in the IgG2a levels between the pTgCPB and pTgCPL groups ( $\mathrm{P}>0.05)$.

\section{Cytokine production}

The splenocyte supernatant was harvested at different times and used to measure cytokine production (interferon- $\gamma[$ IFN- $\gamma]$, interleukin-4 [IL-4] and IL-10) in the different groups. As shown in Table 5, mice vaccinated with $\mathrm{p}$ TgCPB/TgCPL generated significantly higher levels of IFN- $\gamma$ than mice vaccinated with pTgCPB, pTgCPL, PBS, or an empty vector $(\mathrm{P}<0.05)$. The level of IFN- $\gamma$ in the pTgCPB-immunized mice was higher than that of the pTgCPL-immunized mice, but the difference was not statistically significant $(\mathrm{P}>0.05)$. In addition, the low levels of IL-4 and IL-10 seen in the experimental and control groups suggested no statistically significant differences among the groups $(\mathrm{P}>0.05)$. IFN- $\gamma$ and IL-2 favor Th1type immune responses, whereas IL-4 and IL-10 favor
Th2-type responses. These results show that the cellular immune response induced by the single- or multi-gene vaccines tended to be a Th1-type response in the mice.

\section{Protective efficacy of DNA vaccination against $T$. gondii in mice}

To evaluate the level of immunoprotection induced by the DNA vaccines, all of the mice were challenged intraperitoneally with the $T$. gondii $\mathrm{RH}$ strain and mortality was monitored daily until all of the mice showed signs of illness and were killed (Figure 7). Mice immunized with the DNA vaccines had dramatically higher survival times than did the control groups vaccinated with PBS or pBudCE4.1 $(\mathrm{P}<0.05)$. Mice vaccinated with $\mathrm{pTgCPB} / \mathrm{TgCPL}$ showed a greater survival time than those vaccinated with $\mathrm{pTgCPB}$ or pTgCPL $(\mathrm{P}<0.05)$. However, no significant difference was observed between mice immunized with $\mathrm{pTgCPB}$ and those immunized with pTgCPL $(\mathrm{P}>0.05)$.

\section{Discussion}

Bioinformatics is an established interdisciplinary science related to mathematics, statistics, computer science, physics, biology and medicine [43]. Because of its effectiveness and low cost, it has been widely used to predict the structure, function and antigenic epitopes of proteins by estimation of the similarity of the protein of interest to a sequence of known structure or function $[44,45]$. As previously described, we initially used DNAStar software to analyze the secondary structures of TgCPB and TgCPL, followed by DNAMAN software to analyze their sequences from which we identified many good liner-B cell epitopes. Secondly, we used two online services (IEDB and SYFPEITHI) for analyzing Th-cell epitopes and found several potential Th-cell epitopes on TgCPB and TgCPL.

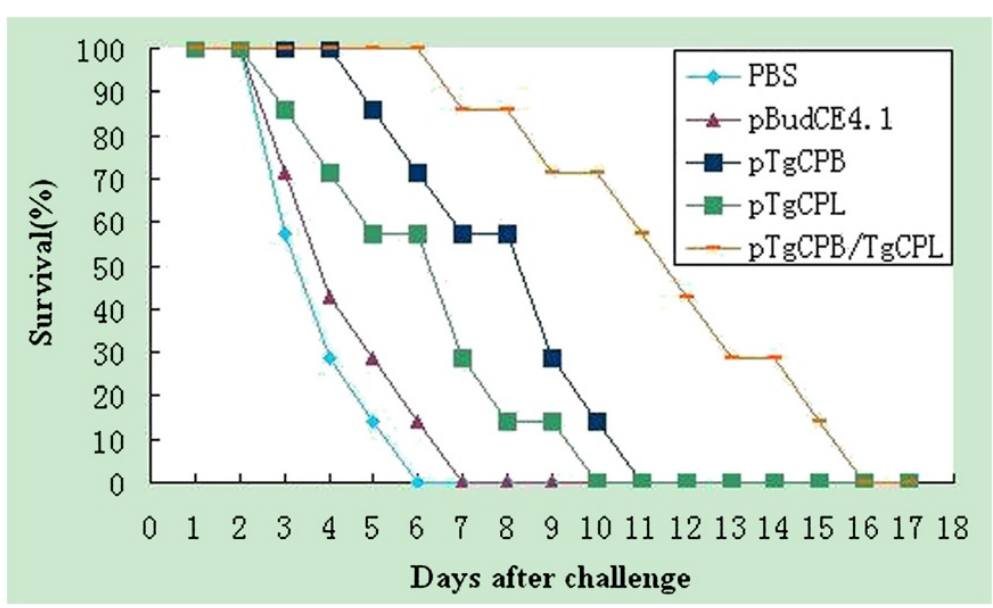

Figure 7 Survival curves of the vaccinated BALB/c following Toxoplasma gondii challenge infections. 10 mice per group were challenged with $1 \times 10^{4}$ tachyzoites of the virulent $T$. gondii $\mathrm{RH}$ strain on the $4^{\text {th }}$ week after the final immunization. Survival was monitored daily for 18 days post-challenge with the parasites. 
Through the animal experiments, we confirmed that both $\mathrm{TgCPB}$ and $\mathrm{TgCPL}$ can induce strong humoral and cellular immune responses and noted a significantly higher level of total IgG antibodies, IgG2a, and IFN- $\gamma$ than that observed for the controls. These results show that $\operatorname{TgCPB}$ and $\operatorname{TgCPL}$ make good vaccine antigens, thus highlighting the reliability of the bioinformatics approaches that were used herein.

In the present study, we successfully constructed pTgCPB and pTgCPL single-gene vaccines and a $\mathrm{p} \operatorname{TgCPB} / \operatorname{TgCPL}$ multi-gene vaccine. Both single- and multi-gene vaccines produced humoral and cellular immune responses in the murine host. The multi-gene vaccine was superior to the single-gene vaccine; it elicited stronger immune responses and more effective protection against $T$. gondii infection. Importantly, all of the mice in the experimental groups immunized with $\mathrm{pTgCPB}, \mathrm{p} \operatorname{TgCPL}$, or $\mathrm{p} \operatorname{TgCPB} / \operatorname{TgCPL}$ displayed strong humoral immune responses as shown by their high IgG levels. The high levels of IgG2a and IFN- $\gamma$ and low levels of IL- 4 and IL-10 suggest that the cellular immune responses were mediated by Th- 1 cells $[46,47]$. These experiments were conducted in $\mathrm{BALB} / \mathrm{c}$ mice; however, it would be interesting to test other strains of mice with different $\mathrm{MCH}$ backgrounds to investigate the range of immune responses to the vaccines.

The survival times of all of the mice in the five groups after intraperitoneal challenge with $1 \times 10^{4}$ tachyzoites of the virulent RH strain of $T$. gondii were recorded. Compared to the mice in the control groups, the immunized mice showed protection against $T$. gondii infection: all mice in the control groups showed signs of illness and were killed within 8 days post-challenge, whereas mice immunized with $\mathrm{p} \operatorname{TgCPB}$, p TgCPL, or pTgCPB/TgCPL had significantly increased survival rates. Mice immunized with $\mathrm{p} \operatorname{TgCPB} / \mathrm{TgCPL}$ showed stronger humoral and cellular immune responses and significantly prolonged survival times than mice in the $\mathrm{p} \operatorname{TgCPB}$ and $\mathrm{pTgCPL}$ groups. All of the mice showed signs of illness and were killed by day 16 post-challenge. The results indicate, therefore, that the DNA vaccines did not provide complete protection against T. gondii RH tachyzoite infection.

Finally, the pBudCE4.1 vector should be mentioned. This vector was chosen to for expression of the multigene vaccine because it has two promoters (CMV and $\mathrm{EF}-1 \alpha$ ), thus ensuring that $\operatorname{TgCPB}$ and $\operatorname{TgCPL}$ can both be expressed whilst avoiding mutual interference.

\section{Conclusions}

In this study, we used bioinformatics approaches to identify antigenic epitopes on $\mathrm{TgCPB}$ and TgCPL proteases. Thereafter, we made single-gene (pTgCPB and pTgCPL) and multi-gene (pTgCPB/TgCPL) DNA vaccines to evaluate the level of immunoprotection induced in mice immunized with such vaccines. The experimental results are consistent with the bioinformatics predictions that the antigenic epitopes on these proteins should induce appropriate immune responses. Hence, these results show that bioinformatics analyses to predict antigenic epitopes on proteins can be a useful tool for vaccine research. When the vaccinated mice were given a challenge infection with $T$. gondii $\mathrm{RH}$ tachyzoites, we found that the DNA vaccine constructs did not provide complete protection against infection, however. Nevertheless, DNA vaccines merit further investigated as a strategy for controlling $T$. gondii infection.

\section{Competing interests}

The authors declare that they have no competing interests.

\section{Authors' contributions}

GZ carried out the experiments and drafted the manuscript. GL and MM revised the manuscript. YB, MS, YH, LW, QZ, HZ, HC and XQZ conducted the experiments and revised the manuscript. $\mathrm{AZ}$ and $\mathrm{SH}$ conceived and designed the study and revised the manuscript. All of the authors have read and approved the final manuscript.

\section{Acknowledgments}

This work was supported in part by grants from the National Natural Science Foundation of China (Grant Nos. 81071373 and 81271857), the State Key Laboratory of Veterinary Etiological Biology (Grant No. SKLVEB2011KFKT005), and the Shandong Provincial Natural Science Foundation (Grant No. ZR2009CM079). XQZ receives support from the National Natural Science Foundation of China (Grant Nos. 31172316, 31230073 and 31101812).

\section{Author details}

'Department of Parasitology, Shandong University School of Medicine, Jinan, Shandong Province 250012, P R China. '2Department of Pediatrics, Provincial Hospital Affiliated to Shandong University, Shandong University School of Medicine, Jinan, Shandong Province 250021, P R China. ${ }^{3}$ State Key Laboratory of Veterinary Etiological Biology, Key Laboratory of Veterinary Parasitology of Gansu Province, Lanzhou Veterinary Research Institute, CAAS, Lanzhou, Gansu Province, P. R. China.

Received: 1 March 2013 Accepted: 1 May 2013

Published: 7 May 2013

\section{References}

1. Dubey JP, Su C: Population biology of Toxoplasma gondii: what's out and where did they come from. Memórias do Instituto Oswaldo Cruz 2009, 104(2):190-195.

2. Dubey JP: The history of Toxoplasma gondii-the first 100 years. J Eukaryot Microbiol 2008, 55(6):467-475.

3. Montoya JG, Liesenfeld O: Toxoplasmosis. Lancet 2004, 363(9425):1965-1976.

4. Robert-Gangneux F, Darde ML: Epidemiology of and diagnostic strategies for toxoplasmosis. Clin Microbiol Rev 2012, 25(2):264-296.

5. Luft BJ, Hafner R, Korzun AH, Leport C, Antoniskis D, et al: Toxoplasmic encephalitis in patients with the acquired immunodeficiency syndrome. N Engl J Med 1993, 329(14):995-1000.

6. Afonso C, Paixão VB, Costa RM: Chronic Toxoplasma infection modifies the structure and the risk of host behavior. PLoS One 2012, 7(3):e32489 p.

7. Dass SA, Vasudevan A, Dutta D, Soh L, Sapolsky RM, et al: Protozoan parasite Toxoplasma gondii manipulates mate choice in rats by enhancing attractiveness of males. PLoS One 2011, 6(11):e27229 p.

8. Haroon F, Händel U, Angenstein F, Goldschmidt J, Kreutzmann P, et al: Toxoplasma gondii actively inhibits neuronal function in chronically infected mice. PLoS One 2012, 7(4):e35516 p.

9. Bhopale GM: Development of a vaccine for toxoplasmosis: current status. Microbes and Infection 2003, 5(5):457-462.

10. Hiszczynska-Sawicka E, Holec-Gasior L, Kur J: DNA vaccines and recombinant antigens in prevention of Toxoplasma gondii infections-current status of the studies. Wiadomości Parazytologiczne 2009, 55(2):125-139. 
11. Liu $Q$, Singla LD, Zhou H: Vaccines against Toxoplasma gondii: status, challen ges and future directions. Hum Vaccin Immunother 2012, 8(9):1305-1308.

12. Barrett AJ, Kirschke H: Cathepsin B, Cathepsin H, and Cathepsin L. Methods Enzymol 1981, 80:535-561.

13. Amuthan G, Biswas G, Zhang SY, Klein-Szanto A, Vijayasarathy C, et al: Mitochondria-to-nucleus stress signaling induces phenotypic changes, tumor progression and cell invasion. EMBO J 2001, 20(8):1910-1920.

14. Guicciardi ME, Deussing J, Miyoshi H, Bronk SF, Svingen PA, et al: Cathepsin B contributes to TNF-alpha-mediated hepatocyte apoptosis by promoting mitochondrial release of cytochrome c. J Clin Investig 2000, 106(9):1127-1137

15. Dou Z, Carruthers VB: Cathepsin proteases in Toxoplasma gondii. Advances in Experimental Medicine and Biology 2011, 712:49-61.

16. Que X, Ngo H, Lawton J, Gray M, Liu Q, et al: The cathepsin B of Toxoplasma gondii, toxopain-1, is critical for parasite invasion and rhoptry protein processing. J Biol Chem 2002, 277(28):25791-25797.

17. Parussini F, Coppens I, Shah PP, Diamond SL, Carruthers VB: Cathepsin L occupies a vacuolar compartment and is a protein maturase within the endo/exocytic system of Toxoplasma gondii. Mol Microbiol 2010, 76(6):1340-1357

18. Miranda K, Pace DA, Cintron R, Rodrigues JC, Fang J, et al: Characterization of a novel organelle in Toxoplasma gondii with similar composition and function to the plant vacuole. Mol Microbiol 2010, 76(6):1358-1375.

19. Huang R, Que X, Hirata K, Brinen LS, Lee JH, et al: The cathepsin L of Toxoplasma gondii (TgCPL) and its endogenous macromolecular inhibitor, toxostatin. Mol Biochem Parasitol 2009, 164(1):86-94.

20. Harper JM, Huynh MH, Coppens I, Parussini F, Moreno S, et al: A cleavable propeptide influences Toxoplasma infection by facilitating the trafficking and secretion of the TgMIC2-M2AP invasion complex. Molecular Biology of the Cell 2006, 17(10):4551-4563.

21. El Hajj H, Papoin J, Cérède O, Garcia-Réguet N, Soête M, et al: Molecular signals in the trafficking of Toxoplasma gondii protein MIC3 to the micronemes. Eukaryotic Cell 2008, 7(6):1019-1028.

22. Rabenau KE, Sohrabi A, Tripathy A, Reitter C, Ajioka JW, et al: TgM2AP participates in Toxoplasma gondii invasion of host cells and is tightly associated with the adhesive protein TgMIC2. Mol Microbiol 2001, 41(3):537-547.

23. Brydges SD, Sherman GD, Nockemann S, Loyens A, Däubener W, et al: Molecular characterization of TgMIC5, a proteolytically processed antigen secreted from the micronemes of Toxoplasma gondii. Mol Biochem Parasitol 2000, 111(1):51-66.

24. Que X, Wunderlich A, Joiner KA, Reed SL: Toxopain-1 is critical for infection in a novel chicken embryo model of congenital toxoplasmosis. Infect Immun 2004, 72(5):2915-2921.

25. Teo CF, Zhou XW, Bogyo M, Carruthers VB: Cysteine protease inhibitors block Toxoplasma gondii microneme secretion and cell invasion. Antimicrob Agents Chemother 2007, 51(2):679-688.

26. Larson ET, Parussini F, Huynh MH, Giebel JD, Kelley AM, et al: Toxoplasma gondii cathepsin I is the primary target of the invasion inhibitory compound LHVS. J Biol Chem 2009, 284(39):26839-26850.

27. Gao J, Faraggi E, Zhou Y, Ruan J, Kurgan L: BEST: improved prediction of B-cell epitopes from antigen sequences. PLoS One 2012, 7(6):e40104 p.

28. Van Regenmortel MH: What is a B-cell epitope? Methods in Molecular Biology 2009, 524:3-20.

29. Tong JC, Tammi MT: Prediction of protein allergenicity using local description of amino acid sequence. Front Biosci 2008, 13:6072-6078.

30. Carter JM, Loomis-Price L: B cell epitope mapping using synthetic peptides. Current Protoc Immunol 2004. doi:10.1002/0471142735.im0904s60. Chapter 9:Unit 9.4.

31. Kyte J, Doolittle RF: A simple method for displaying the hydropathic character of a protein. J Mol Biol 1982, 157(1):105-132

32. Welling GW, Weijer WJ, van der Zee R, Welling-Wester S: Prediction of sequential antigenic regions in proteins. FEBS Lett 1985, 188(2):215-218.

33. Subramani A, Floudas CA: Structure prediction of loops with fixed and flexible stems. The Journal of Physical Chemistry. B 2012, 116(23):6670-6682.

34. Gershoni JM, Stern B, Denisova G: Combinatorial libraries, epitope structure and the prediction of protein conformations. Immunol Today 1997, 18(3):108-110

35. El-Kady IM: T-cell immunity in human chronic toxoplasmosis. J Egypt SoC Parasitol 2011, 41(1):17-28.

36. Bhasin M, Lata S, Raghava GP: Searching and mapping of T-cell epitopes, MHC binders, and TAP binders. Methods in Molecular Biology 2007, 409:95-112.
37. Vider-Shalit T, Louzoun Y: MHC-I prediction using a combination of T cell epitopes and MHC-I binding peptides. J Immunol Methods 2011, 374(1-2):43-46.

38. Zhou H, Min J, Zhao Q, Gu Q, Cong H, et al: Protective immune response against Toxoplasma gondii elicited by a recombinant DNA vaccine with a novel genetic adjuvant. Vaccine 2012, 30(10):1800-1806.

39. Cui X, Lei T, Yang D, Hao P, Li B, Liu Q: Toxoplasma gondii immune mapped protein-1 (TgIMP1) is a novel vaccine candidate against toxoplasmosis. Vaccine 2012, 30(13):2282-2287.

40. Min J, Qu D, Li C, Song X, Zhao Q, et al: Enhancement of protective immune responses induced by Toxoplasma gondii dense granule antigen 7 (GRA7) against toxoplasmosis in mice using a prime-boost vaccination strategy. Vaccine 2012, 30(38):5631-5636.

41. Constant S, Pfeiffer C, Woodard A, Pasqualini T, Bottomly K: Extent of T cell receptor ligation can determine the functional differentiation of naive CD4+ T cells. The Journal of Experimental Medicine 1995, 182(5):1591-1596.

42. Chaturvedi P, Yu Q, Southwood S, Sette A, Singh B: Peptide analogs with different affinites for MHC alter the cytokine profile of T helper cells. Int Immunol 1996, 8(5):745-755

43. Romano P, Giugno R, Pulvirenti A: Tools and collaborative environments for bioinformatics research. Briefings in Bioinformatics 2011, 12(6):549-561.

44. Martin DM, Berriman M, Barton GJ: GOtcha: a new method for prediction of protein function assessed by the annotation of seven genomes. BMC Bioinforma 2004, 5:178.

45. Bai Y, He S, Zhao G, Chen L, Shi N, Zhou H, Cong H, Zhao Q, Zhu XQ: Toxoplasma gondii: bioinformatics analysis, cloning and expression of a novel protein TgIMP1. Exp Parasitol 2012, 132(4):458-464.

46. Mannie MD: Do holes in the T-cell repertoire have a center-surround regulatory structure? A rationale for the bifurcation of the Th1 and Th2 pathways of differentiation. Medical Hypotheses 1997, 8(3):261-265.

47. Schaeffer EB, Sette A, Johnson DL, Bekoff MC, Smith JA, Grey HM, Buus S: Relative contribution of "determinant selection" and "holes in the T-cell repertoire" to T-cell responses. Proc Natl Acad Sci USA 1989, 86(12):4649-4653.

doi:10.1186/1471-2334-13-207

Cite this article as: Zhao et al:: Toxoplasma gondii cathepsin proteases are undeveloped prominent vaccine antigens

against toxoplasmosis. BMC Infectious Diseases 2013 13:207.

\section{Submit your next manuscript to BioMed Central and take full advantage of:}

- Convenient online submission

- Thorough peer review

- No space constraints or color figure charges

- Immediate publication on acceptance

- Inclusion in PubMed, CAS, Scopus and Google Scholar

- Research which is freely available for redistribution 